Wright State University

CORE Scholar

Physics Faculty Publications

Physics

$1-2002$

\title{
High Spatial Resolution Thermal Conductivity of Bulk ZnO (0001)
}

Diana I. Florescu

L. G. Mourokh

Fred H. Pollak

David C. Look

Wright State University - Main Campus, david.look@wright.edu

G. Cantwell

See next page for additional authors

Follow this and additional works at: https://corescholar.libraries.wright.edu/physics

Part of the Physics Commons

\section{Repository Citation}

Florescu, D. I., Mourokh, L. G., Pollak, F. H., Look, D. C., Cantwell, G., \& Li, X. (2002). High Spatial Resolution Thermal Conductivity of Bulk ZnO (0001). Journal of Applied Physics, 91 (2), 890-892.

https://corescholar.libraries.wright.edu/physics/706

This Article is brought to you for free and open access by the Physics at CORE Scholar. It has been accepted for inclusion in Physics Faculty Publications by an authorized administrator of CORE Scholar. For more information, please contact library-corescholar@wright.edu. 


\section{Authors}

Diana I. Florescu, L. G. Mourokh, Fred H. Pollak, David C. Look, G. Cantwell, and X. Li 


\title{
AIP Applited Physics
}

\section{High spatial resolution thermal conductivity of bulk $\mathrm{ZnO}(0001)$}

\author{
D. I. Florescu, L. G. Mourokh, Fred H. Pollak, D. C. Look, G. Cantwell et al.
}

Citation: J. Appl. Phys. 91, 890 (2002); doi: 10.1063/1.1426234

View online: http://dx.doi.org/10.1063/1.1426234

View Table of Contents: http://jap.aip.org/resource/1/JAPIAU/v91/i2

Published by the American Institute of Physics.

\section{Related Articles}

Interfacial thermal conductance limit and thermal rectification across vertical carbon nanotube/graphene nanoribbon-silicon interfaces

J. Appl. Phys. 113, 064311 (2013)

Fabrication of Bi2Te3 nanowire arrays and thermal conductivity measurement by $3 \omega$-scanning thermal microscopy

J. Appl. Phys. 113, 054308 (2013)

Investigation on interfacial thermal resistance and phonon scattering at twist boundary of silicon

J. Appl. Phys. 113, 053513 (2013)

Area of contact and thermal transport across transfer-printed metal-dielectric interfaces

J. Appl. Phys. 113, 024321 (2013)

Negative correlation between in-plane bonding strength and cross-plane thermal conductivity in a model layered material

Appl. Phys. Lett. 102, 011901 (2013)

\section{Additional information on J. Appl. Phys.}

Journal Homepage: http://jap.aip.org/

Journal Information: http://jap.aip.org/about/about_the_journal

Top downloads: http://jap.aip.org/features/most_downloaded

Information for Authors: http://jap.aip.org/authors

\section{ADVERTISEMENT}

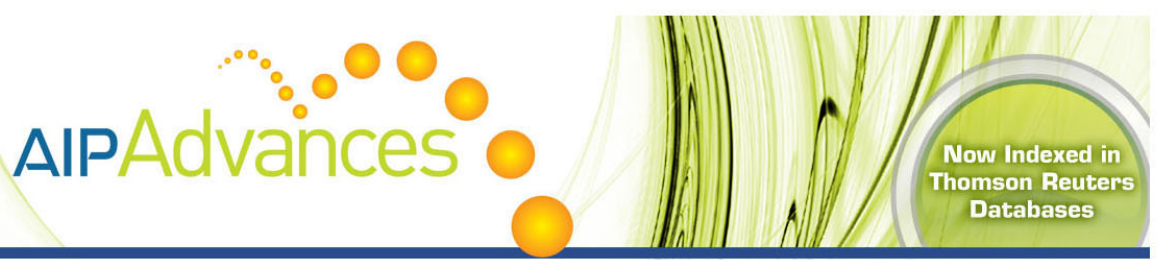

\section{Explore AIP's open access journal: •Rapid publication \\ - Article-level metrics \\ Post-publication rating and commenting}




\section{High spatial resolution thermal conductivity of bulk ZnO (0001)}

D. I. Florescu, ${ }^{\text {a) }}$ L. G. Mourokh, and Fred H. Pollak ${ }^{\text {b) }}$

Physics Department and New York State Center for Advanced Technology in Ultrafast Photonic Materials and Applications, Brooklyn College of the City University of New York, Brooklyn, New York 11210

D. C. Look $^{\mathrm{C})}$

Materials and Manufacturing Directorate, Air Force Research Laboratory, Wright-Patterson Air Force Base, Dayton, Ohio 45433

G. Cantwell

Eagle-Picher Industries, Inc., 200 B.J. Tunnell Boulevard, Miami, Oklahoma 74354

X. Li

ThermoMicroscopes, 1171 Borregas Avenue, Sunnyvale, California 94089

(Received 14 March 2001; accepted for publication 15 October 2001)

We measured high spatial/depth resolution $300 \mathrm{~K}$ thermal conductivity $\kappa$ of the $\mathrm{Zn}$ and $\mathrm{O}$ surfaces of two bulk $n$-type $\mathrm{ZnO}$ (0001) samples, grown by a vapor-phase transport method, using scanning thermal microscopy $(\mathrm{SThM})$. The thermal investigation was performed in both point-by-point $(\sim 2$ $\mu \mathrm{m}$ resolution) and area-scan modes. On the first sample $\kappa=1.16 \pm 0.08$ (Zn face)/1.10 $\pm 0.09(\mathrm{O}$ face) W/cm K while for the second material $\kappa=1.02 \pm 0.07$ ( $\mathrm{Zn}$ face) $/ 0.98 \pm 0.08$ (O face) W/cm K. These are the highest $\kappa$ values reported on $\mathrm{ZnO}$. A correlation between SThM area-scan readings and surface topography was established by simultaneously performing atomic force microscopy scans. The influence of surface roughness on the effective thermal conductivity (i.e., heat flow) is discussed. (C) 2002 American Institute of Physics. [DOI: 10.1063/1.1426234]

$\mathrm{ZnO}$ is a wide band gap $(3.5 \mathrm{eV}) \mathrm{II}-\mathrm{VI}$ semiconductor, which has been used in many applications such as piezoelectric transducers, ${ }^{1}$ varistors, ${ }^{1}$ and laser diodes. ${ }^{2}$ Recently, $\mathrm{ZnO}$ has been recommended as an attractive alternative to both sapphire and $\mathrm{SiC}$ as substrates for $\mathrm{GaN}$ growth. When growing $\mathrm{GaN}$ on (0001) sapphire substrates, one has to cope with a $16 \%$ lattice mismatch. ${ }^{3} \mathrm{SiC}$ is better suited as a substrate material, but is costly and also generates stacking mismatch boundaries in device structures, which shorten the lifetime of the device. For $\mathrm{ZnO}$ the lattice mismatch is only $2.2 \%$ for $\mathrm{GaN}$ and zero for $\mathrm{In}_{0.22} \mathrm{Ga}_{0.78} \mathrm{~N}$. ${ }^{3}$ Since most of these applications are related to high power electronic and optoelectronic devices it is essential to understand the thermal characteristics of $\mathrm{ZnO}$. The thermal conductivity $\kappa$ of solid materials consists of both lattice and electronic contributions. The former is a function of the mean free path of the phonons and hence is determined by both intrinsic (anharmonic phonon-phonon scattering) and extrinsic (phonondefect) scattering. For carrier concentration $\leqslant 10^{19} \mathrm{~cm}^{-3}$ the electronic thermal conductivity is negligible in relation to the lattice portion. The quantity $\kappa$ is of importance from both fundamental (basic mechanism of phonon propagation) and applied (device modeling, sample quality) perspectives.

\footnotetext{
a) Author to whom correspondence should be addressed; present address: EMCORE Corp. 145 Belmont Dr., Somerset, NJ 08873; electronic mail: doru florescu@emcore.com

${ }^{b)}$ Also at: the Graduate School and University Center of the City University of New York, New York, NY 10016; electronic mail: fhpbc@cunyvm.cuny.edu

c)Present address: Semiconductor Research Center, Wright State University, Dayton, OH 45435.
}

We report high spatial/depth resolution $\kappa$ measurements at $300 \mathrm{~K}$ of the $\mathrm{Zn}$ and $\mathrm{O}$ faces of two $n$-type $\mathrm{ZnO}$ (0001) samples fabricated by a vapor-phase technique. The thermal investigation was performed in two ways: point-by-point $(\sim 2 \mu \mathrm{m}$ resolution) and area scans. The area scans are instrumentation limited to approximately $120 \mu \mathrm{m} \times 120 \mu \mathrm{m}$ for one scan, while the point-by-point measurements can be extended to full $8 \mathrm{in}$. wafers. The point-by-point measurements on sample A reveal $\kappa=1.16 \pm 0.08$ (Zn face)/1.10 \pm 0.09 (O face) W/cm K, while for sample B $\kappa=1.02 \pm 0.07$ (Zn face)/ $0.98 \pm 0.08$ ( $\mathrm{O}$ face) $\mathrm{W} / \mathrm{cm} \mathrm{K}$. These are approximately twice higher than the previously reported value of $\sim 0.48 \mathrm{~W} / \mathrm{cm} \mathrm{K}^{4}{ }^{4}$ A correlation between effective $\kappa$ values from the scanning thermal microscopy (SThM) scans and topography was established by simultaneously performing atomic force microscopy (AFM) scans.

The samples used in this study were two $6 \mathrm{~mm} \times 6 \mathrm{~mm}$ $n$-type $\mathrm{ZnO}$ (0001) pieces cut from full 2 in. wafers grown by a vapor-phase technique described elsewhere. ${ }^{1}$ The $\mathrm{Zn}$ and $\mathrm{O}$ faces were produced by a proper chemomechanical polishing method. ${ }^{1}$ The carrier concentration and mobility were previously measured by the temperature-dependent Hall-effect technique. ${ }^{1}$ The sample parameters are shown in

TABLE I. Summary of the sample parameters.

\begin{tabular}{cccccc}
\hline \hline Sample & $\begin{array}{c}\text { Thickness } \\
(\mu \mathrm{m})\end{array}$ & $\begin{array}{c}\text { Mobility } \\
\left(\mathrm{cm}^{2} \mathrm{~V}^{-1} \mathrm{~s}^{-1}\right)\end{array}$ & $\begin{array}{c}\text { Carrier } \\
\text { concentration } \\
\left(\mathrm{cm}^{-3}\right)\end{array}$ & $\begin{array}{c}\kappa \text {-Zn side } \\
(\mathrm{W} / \mathrm{cm} \mathrm{K})\end{array}$ & $\begin{array}{c}\kappa \text {-O side } \\
(\mathrm{W} / \mathrm{cm} \mathrm{K})\end{array}$ \\
\hline A & 650 & 211 & $5.2 \times 10^{16}$ & $1.16 \pm 0.08$ & $1.10 \pm 0.09$ \\
$\mathrm{~B}$ & 565 & 227 & $6.6 \times 10^{16}$ & $1.02 \pm 0.07$ & $0.98 \pm 0.08$ \\
\hline \hline
\end{tabular}




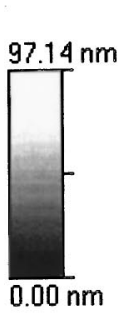

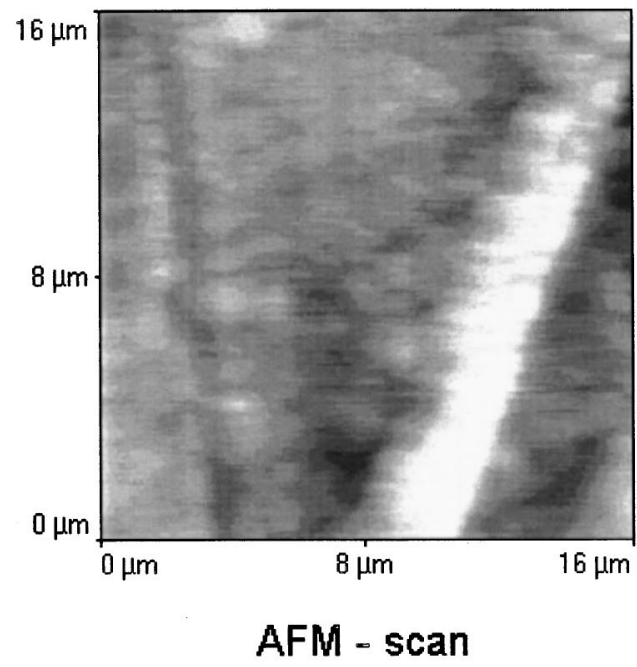

(a)
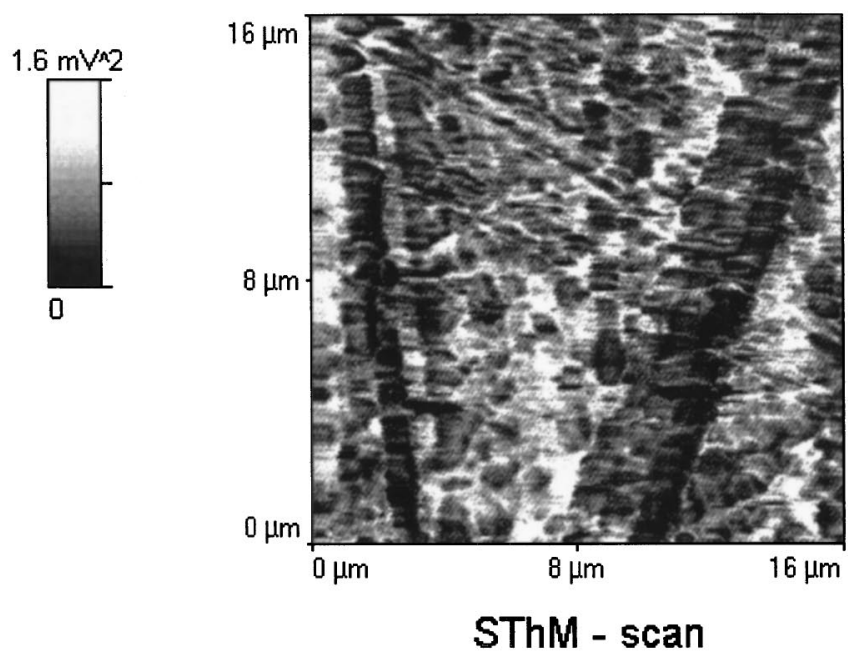

(b)

FIG. 1. (a) AFM and (b) SThM scans on a $16 \mu \mathrm{m} \times 16 \mu \mathrm{m}$ area of the Zn side of sample B. Note the correlation between the SThM and AFM scan features.

Table I. The high spatial resolution thermal conductivity measurements were made using a ThermoMicroscopes AutoProbe M5 SThM/AFM. ${ }^{5}$ A calibration procedure has been developed making it possible to determine absolute values of $\kappa$. The output voltage $V_{\text {out }}^{2}$ has been measured for a series of samples of known thermal conductivity. ${ }^{6,7}$ The resultant linear relation between $V_{\text {out }}^{2}$ and $\kappa$ provides the calibration. AFM scans were acquired concomitantly with SThM area scans using the same tip element.

Table I shows both the $\mathrm{Zn}$ and $\mathrm{O}$ side thermal conductivity results using the point-by-point type measurement technique on both samples. Approximately 15-20 points randomly distributed over the $6 \mathrm{~mm} \times 6 \mathrm{~mm}$ surface area were investigated. The variation is the standard deviation.

AFM and SThM scans are presented in Figs. 1(a) and 1(b), respectively, on a $16 \mu \mathrm{m} \times 16 \mu \mathrm{m}$ area on the $\mathrm{Zn}$ side of sample B. Similar scans were acquired on the $\mathrm{O}$ side, and also on both sides of sample A, and will not be presented herein. SThM scans provide information only on the relative variations of the thermal conductivity. ${ }^{8}$ Note the correlation between the SThM and AFM scan features. SPMLAB V5.01 ${ }^{5}$ was used on the SThM scan to display $\Delta V_{\text {out }}^{2}$ (variations in $\left.V_{\text {out }}^{2}\right)$, which are proportional to the changes in the effective thermal conductivity. Based on our calibration, the $\Delta V_{\text {out }}^{2}$ range observed in Fig. 1(b) corresponds to variations of about $6 \%-7 \%$ in $\kappa$. This is consistent with the deviations reported in Table I for the point-by-point type measurements.

The following question arises: are these small variations in the observed $V_{\text {out }}^{2}$ an intrinsic material property, i.e., changes in the actual thermal conductivity, or just the effect of surface topography? Several factors, such as the contact resistance between tip and probe, the temperature distribution along the tip, the contact force, the surrounding temperature, humidity, and gas are influencing the voltage reading when the tip is in contact with the specimen. ${ }^{8,9}$ Since the calibration and measurements are performed under the exact same conditions, the only factor that differs from sample to sample is the surface topography. For a perfectly flat surface the contact between the probe tip (radius of curvature $\sim 1$ $\mu \mathrm{m})^{6,7}$ and the surface is very small, with spatial resolutions higher than the actual tip dimension being reported for SThM scans. ${ }^{10}$ For rough surfaces, while scanning or positioning, the tip could impinge on a valley-like feature [Fig. 2(a)], or a hillock [Fig. 2(b)]. We performed a calculation of the effective heat flow for topographical features with radius of curvature $r_{c}$ ( \pm for hillock/valley), and height/depth $h$ $\left(|h| \leqslant\left|r_{c}\right|\right)$, assuming in-plane symmetry (see Fig. 2). For a perfectly flat surface $r_{c} \rightarrow \infty, h \rightarrow 0$. As seen in Fig. 1(a) the height variations when scanning across the sample are in the $0-100 \mathrm{~nm}$ range. For $20 \mathrm{~nm}<|h|<100 \mathrm{~nm}$ and $\left|r_{c}\right|$ $\leqslant 10 \mu \mathrm{m}$ the results show that the difference in heat flow in relation to the flat surface is about $7 \%-12 \%$, being negative/ positive for hillock/valley. For $\left|r_{c}\right|>10 \mu \mathrm{m}$ this difference is even less. Hence, a valley will lead to an increased thermal signal, and vice versa. Thus topography can have an inverted effect on the thermal conductivity measurements, as shown in Fig. 1.

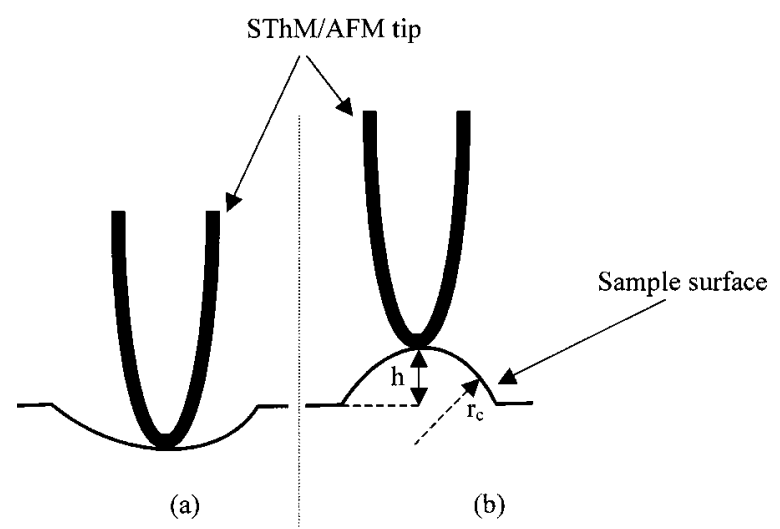

FIG. 2. Geometry of SThM/AFM tip and sample surface interaction. The tip can be (a) in a valley, or (b) on top of a hillock. The parameter $r_{c}$ is the hillock/valley radius of curvature, and $h$ is the height/depth from the sample surface. 
The noticeable difference in spatial resolutions between the AFM and SThM scans is related to changes in the effective heat flow between the scanning probe and sample surface, which are more significant on the voltage, i.e., thermal readings, than on AFM topography readings. Features as small as $0.5 \mu \mathrm{m}$ and up to $\sim 3 \mu \mathrm{m}$ wide are clearly resolved by both the AFM and SThM scans, as shown in Fig. 1. However, the experimental voltage variations $\Delta V_{\text {out }}^{2}$ correspond to only $6 \%-7 \%$ changes in the thermal conductivity. In this case $\kappa$ variations are probably the effect of topography. Higher variations $(>12 \%)$ in the SThM $V_{\text {out }}^{2}$ reading (proportional to $\kappa$ ) for AFM topographical features with heights $<100 \mathrm{~nm}$ would be an indication of intrinsic thermal conductivity variations across the area under investigation.

In conclusion, by using SThM we have performed high spatial/depth resolution thermal conductivity measurements at $300 \mathrm{~K}$ of two $n$-type $\mathrm{ZnO}(0001)$ samples grown by a vapor-phase transport method. Point-by-point and area-scan type measurements were employed. On the $\mathrm{Zn}(\mathrm{O})$ side we found $\kappa=1.16 \pm 0.08(1.10 \pm 0.09) \mathrm{W} / \mathrm{cm} \mathrm{K}$ on sample A, and $\kappa=1.02 \pm 0.07(0.98 \pm 0.08) \mathrm{W} / \mathrm{cm} \mathrm{K}$ on sample B. To date these are the highest reported thermal conductivity values on $\mathrm{ZnO}$. A correlation between the surface topography and thermal conductivity variations was established by acquiring the AFM and SThM scans concomitantly during the area scan.
The effects of surface roughness on effective $\kappa$ values, i.e., heat flow, were discussed in terms of tip-surface geometry.

Three of the authors (D.I.F., L.G.M., and F.H.P.) acknowledge the Office of Naval Research support under Contract No. N00014-99-C-0663, administered by Dr. Colin Wood, and the New York State Office of Science, Technology, and Academic Research through its Centers for Advanced Technology program. D.C.L. was supported by U.S. Air Force Contract No. F33615-00-C-5402.

${ }^{1}$ D. C. Look, D. C. Reynolds, J. R. Sizelove, R. L. Jones, C. W. Litton, G. Cantwell, and W. C. Harsch, Solid State Commun. 105, 399 (1998).

${ }^{2}$ Y. Chen, D. Bagnall, and T. Yao, Mater. Sci. Eng., B 75, 190 (2000).

${ }^{3}$ J. Nause, III-V Review 12, 28 (1999).

${ }^{4}$ T. Tsubota, M. Ohtaki, K. Eguchi, and H. Arai, J. Mater. Chem. 8, 409 (1998).

${ }^{5}$ ThermoMicroscopes/Park Instruments, 1171 Borregas Avenue, Sunnyvale, CA 94089.

${ }^{6}$ D. I. Florescu, L. G. Mourokh, V. M. Asnin, F. H. Pollak, and R. J. Molnar, Mater. Res. Soc. Symp. Proc. 595, 3.89 .1 (2000).

${ }^{7}$ F. Ruiz, W. D. Sun, F. H. Pollak, and C. Venkatraman, Appl. Phys. Lett. 73, 1802 (1998); D. I. Florescu, V. M. Asnin, and F. H. Pollak, Comp. Semi. Mag. 7, 62 (2001).

${ }^{8}$ A. Hammiche, H. M. Pollock, M. Song, and D. J. Thurston, Meas. Sci. Technol. 7, 142 (1996).

${ }^{9}$ S. Callard, G. Tallarida, A. Borghesi, and L. Zanotti, J. Non-Cryst. Solids 245, 203 (1999).

${ }^{10}$ L. J. Balk, M. Maywald, and R. J. Pylkki, Inst. Phys. Conf. Ser. 146, 655 (1995). 